\title{
Integrando abordagens da economia e da sociologia em análises da produção tecnológica
}

Recebimento: 09.09.2009 Aprovado: 12.12.2009
Cristiane Vianna Rauen

Léa Velho ${ }^{1}$

Resumo: Os enfoques disciplinares para tratar a produção do conhecimento em ciência e tecnologia, em geral, e os artefatos tecnológicos, em particular, são reconhecidamente insuficientes. Mesmo assim, a interação é muito fraca entre aqueles que estudam a construção de artefatos tecnológicos com abordagens sociológicas e aqueles que o fazem a partir de enfoques econômicos. Aproximar essas duas vertentes de análise, identificando suas diferenças e, principalmente, seus pontos convergentes é do que se trata esse artigo. Enquanto a Economia tende a não incorporar elementos importantes para a compreensão desse processo tais como, os interesses dos atores sociais, as estruturas de poder e a influência dos aspectos políticos, a Sociologia desconsidera algumas das características fundamentais para a estrutura econômica de produção tecnológica, como agências, instituições e sistemas econômicos. O resultado é o surgimento de espaços ociosos de análise que poderiam ser mais bem explorados se houvesse interdisciplinaridade. Este trabalho explora as possibilidades de entrecruzamentos do enfoque econômico, representado pela Economia Evolucionária (EE), e do sociológico, representado por dois ramos da Sociologia do Conhecimento Científico: a Social Construction of Technology (SCOT) e a Actor Network Theory (ANT), argumentando que as categorias de análise de um e outros se complementam, oferecendo uma caracterização mais consistente da produção do artefato tecnológico.

Palavras-chave: Produção tecnológica, Economia evolucionária, Sociologia da Tecnologia
1. Cristiane Vianna Rauen é doutoranda em teoria econômica pelo IE/Unicamp, mestre em política científica e tecnológica pelo DPCT - IG/ Unicamp e pesquisadora do Núcleo de Economia Industrial e da Tecnologia (Neit - IE/Unicamp). Instituto de Economia, Caixa

Postal 61352

Universidade Estadual de Campinas (Unicamp) 13083-857, Campinas, São Paulo, Brasil crisrauen@gmail.com. Léa Velho é professora titular do Departamento de Política Científica e Tecnológica do IG/ Unicamp, Instituto de Geociências, Caixa Postal 6152, 13083-970, Campinas, São Paulo, Brasil velho@ige.unicamp.br. 


\section{Introdução}

$\left[\begin{array}{l}\text { temática da mudança tecnológica tem sido, desde o início do século } \\ x x \text {, foco de interesse de diversas áreas do conhecimento que, na } \\ \text { grande maioria dos casos, conduzem a análises estritamente disci- }\end{array}\right.$ plinares. De modo geral, pode-se dizer que a maioria dos programas ou grupos de pesquisa que trata da produção de artefatos tecnológicos adota um enfoque predominantemente sociológico ou econômico. Enquanto os estudos econômicos se atêm majoritariamente às premissas determinísticas da produção tecnológica, com base em conceitos como "trajetória tecnológica" e "seleção natural", os estudos da sociologia se atêm ao papel dos indivíduos ou grupos de indivíduos envolvidos nesse processo, seus interesses e os conflitos que fazem parte da construção do artefato tecnológico.

Os diferentes aspectos enfocados por cada uma dessas perspectivas analíticas produzem espaços ociosos de análise que poderiam ser mais bem explorados caso houvesse um esforço de complementaridade entre elas. Tanto as análises econômicas como as sociológicas ignoram elementos importantes para a compreensão do processo de produção da tecnologia. A primeira não considera os condicionantes sociais - tais como os interesses dos atores envolvidos, as estruturas de poder e a influência dos aspectos políticos - e a segunda não incorpora alguns elementos fundamentais para a estrutura econômica de produção tecnológica - como agências, instituições e sistemas econômicos.

Apesar de adotarem perspectivas diferentes sobre o objeto de análise, tanto a economia - através da abordagem evolucionária - como a sociologia - com os enfoques socialconstrutivistas - têm se direcionado, nos anos recentes, a análises mais complexas e explícitas da mudança tecnológica. Assim, pode-se dizer que estas duas disciplinas têm caminhado em linhas paralelas, ambas tentando, com base em seus conceitos e em suas ferramentas próprias, abrir a caixa preta da inovação tecnológica (Coombs et alii, 1992). Esse movimento em uma direção comum fez com que ambas as disciplinas se voltassem para pontos de análise similares e complementares.

Muito embora ainda haja certa resistência na integração disciplinar, a proposta deste artigo está relacionada à defesa de uma análise multidisciplinar sobre a produção de conhecimento científico e tecnológico, em geral, e sobre a produção de artefatos tecnológicos, em especial. Com base nisso, são exploradas as possibilidades de entrecruzamentos das linhas de pensa- 
mento econômico, representada pela economia evolucionária (EE), e sociológica, representada por dois ramos da sociologia da tecnologia: a abordagem social construction of technology (SCOT) e a actor network theory (ANT), com base no pressuposto de que alguns de seus elementos de análise se complementam de forma a permitir uma caracterização mais consistente e ampla da produção de artefatos tecnológicos.

Reconhece-se que os enfoques aqui selecionados para análise, assim como as categorias analíticas que constituem cada um deles, não são estáticos. Ou seja, os conceitos e categorias destacadas como representativos de cada enfoque foram sendo modificados no decorrer do tempo, e não têm necessariamente o mesmo significado para todos os autores que os utilizam. Além disso, alguns dos conceitos aqui apresentados não são exclusivos do enfoque econômico ou sociológico. Quando se usa, por exemplo, o conceito de path-dependence, sabe-se que ele é amplamente utilizado por outras disciplinas que não a economia, sendo mesmo empregado em estudos da própria sociologia, e que tanto esse quanto outros conceitos são dinâmicos e podem ser apropriados por outras linhas ou mesmo agregados a novos.

No entanto, este trabalho se propõe a apresentar um exercício de integração de três abordagens específicas que se dedicam ao estudo da construção de artefatos tecnológicos e, para tanto, apresenta seus conceitos mais emblemáticos e originais aplicados a estes tipos de estudos. Assim, é possível dar exclusividade ao conceito de path-dependence à economia evolucionária, uma vez que nem SCOT nem ANT o empregavam em seus artigos seminais.

Dessa forma, este artigo apresenta, sucintamente, na sua primeira seção, os principais conceitos e categorias analíticas de cada uma das abordagens, suas fragilidades e os pontos de análise similares e complementares das demais abordagens aqui consideradas. A segunda seção apresenta estudos de caso de produção de artefatos tecnológicos provenientes dessas abordagens. Os três casos são, então, revisitados à luz dos conceitos e das categorias analíticas provenientes das demais abordagens, para que assim seja possível identificar tanto a diferença no modo como cada uma analisa os casos em questão, quanto a possibilidade de complementaridade entre elas.

Os casos escolhidos exploram o desenvolvimento de tecnologias que se utilizam de uma matriz energética de interesse comum para as três abordagens. Estes são: $a$. o caso do refrigerador elétrico, de Ruth Cowan (1993), que usa o enfoque da construção social da tecnologia (SCOT); $b$. o caso 
seminal do veículo elétrico, de Michel Callon (1980), um dos propositores da teoria ator-rede (ANT); e c. o caso do veículo elétrico, de Robin Cowan e Hultèn (1996), representantes da economia evolucionária (EE).

É importante enfatizar que a retomada dos casos é um exercício inicial de apresentação das fragilidades das abordagens originais que justifica a necessidade de maior completude analítica, o que poderia, de acordo com a defesa a que se propõe este artigo, se tornar possível a partir da integração das demais abordagens propostas.

\section{Integrando as análises da EE, SCOT e ANT}

No pensamento econômico ortodoxo, a produção tecnológica é analisada de forma estática, baseada no modelo de função de produção. A EE afastase desta ideia e concebe a produção tecnológica como oriunda de um ambiente concorrencial permeado pela incerteza, fruto de um processo estocástico e de desequilíbrio contínuo. Assim, para essa escola de pensamento, a inovação é tida como central à dinâmica capitalista, resultante de um processo bastante dinâmico, quase vivo, e que, portanto, encontra paralelos em referenciais teóricos como o da biologia.

Com base nisso, foram introduzidos pela abordagem EE conceitos emprestados da teoria darwiniana de seleção natural para a compreensão dos fatores determinantes do processo inovativo. Tais conceitos são:

a. rotinas, que cumprem o papel dos genes nas firmas inovadoras, constituindo-se no principal fator de identificação comportamental dos agentes e das instituições em dado sistema econômico (Nelson e Winter, 1982);

b. ambiente de seleção e seleção natural, que determina de que forma o uso relativo de diferentes tecnologias muda com o passar do tempo, além de influenciar tanto o padrão do crescimento em produtividade gerado por cada inovação quanto os tipos de P\&D que as firmas e a indústria acharão mais lucrativos para serem tomados (Nelson e Winter, 1977);

c. trajetórias naturais e trajetórias tecnológicas, que identificam as direções em que determinada inovação avança em seu processo de busca, que seguem determinados "padrões de atividade normais de soluções de problemas, isto é, de progresso dentro de dado paradigma tecnológico" (Dosi, 1982: 152), e que, "além de expressarem dado momentum 
interno da mudança tecnológica, devem ser consideradas inerentemente boas estratégias de desenvolvimento justamente pelo fato de terem sido perseguidas de forma natural" (Nelson e Winter, 1977: 56).

d. regimes tecnológicos e paradigmas tecnológicos, que são, também de acordo com os autores acima citados, os sinalizadores das trajetórias a partir das quais o progresso tecnológico se torna possível, e que estão baseadas tanto em conhecimentos específicos para a solução de problemas tecnológicos, quanto nas crenças dos técnicos sobre o que é factível ou o que vale a pena ser tentado.

Além das analogias biológicas, a abordagem EE oferece outros importantes conceitos, como:

e. path-dependence, irreversibilidade e lock-in, que também podem estar incluídos na gama de elementos que abrem espaço para a acusação de determinismo excessivo da EE na análise da produção tecnológica, pois sinalizam que, uma vez traçada dada trajetória tecnológica, a interdependência entre seus componentes impossibilita o retorno ao caminho anterior ou uma nova trajetória (Rosenberg, 1982);

f. projeto dominante, definido como "aquele que adquire a fidelidade do mercado, aquele que os concorrentes e inovadores precisam adotar para terem pelo menos a esperança de dominar uma parcela significativa do mercado sucessor" (Utterback, 1996: 26);

g. inovações radicais e inovações revolucionárias, que, de acordo com Freeman (1984), geram efeitos profundos sobre a economia, alterando inclusive seu sistema social e político; e

h. Sistemas Nacionais de Inovação (SNIs) e Sistemas Setoriais de Inovação (SSIs), conceitos introduzidos por diversos autores da EE como, Lundvall $(1988,1992)$; Freeman (1988); Nelson e Rosenberg (1993); e Malerba (2002), que são, em geral, definidos como redes de instituições nos setores públicos e privados cujas atividades e interações iniciam, importam, modificam e difundem novas tecnologias.

Mesmo tendo avançado no sentido de explorar a caixa preta da inovação tecnológica, esses conceitos da EE não conseguem suprir as deficiências analíticas na medida em que mantêm uma visão institucionalizada e prede- 
finida do papel dos agentes e negligenciam a influência dos fatores sociais no processo de produção tecnológica (MacKenzie, 1992; Vergragt, 1988; Bruun \& Hukkinen, 2003).

Como contrapartida, introduzimos a revisão da abordagem SCOT, que delega ao ambiente social, mais especificamente aos grupos sociais relevantes (GSR), o papel de construtores da tecnologia, que é, portanto, direcionada estritamente por processos sociais e não por qualquer lógica tecnológica inerente. De acordo com a abordagem SCOT, o design final do artefato tecnológico é atingido quando se dá o fechamento e a subsequente estabilização das controvérsias tecnológicas, ou seja, quando há o alcance do consenso entre grupos que atribuem diferentes significados ao artefato, num processo denominado flexibilidade interpretativa.

Outros conceitos importantes para a análise SCOT na produção tecnológica são: $a$. as estruturas tecnológicas, que, de acordo com Bijker (1987), correspondem aos diferentes conceitos, objetivos e técnicas empregados no processo de construção do artefato; $b$. os diferentes graus de inclusão que os GSR associados ao artefato possuem; e $c$. a percepção de poder, que é responsável pelo processo de fixação de significados ao artefato (Bijker, 1995). Desse último conceito deriva o caráter de obstinação da construção da tecnologia, já que a fixação de significados limita a flexibilidade de significados subsequentes, tornando seus embricamentos mais obstinados.

Apesar de avançarem na caracterização sociológica do processo de produção da tecnologia distanciando-se da ideia de que a mudança tecnológica deriva de uma trajetória natural, a abordagem SCOT não escapa de críticas relacionadas aos conceitos que a fundamentam. Essas críticas referem-se principalmente ao fato de que os GSR são tomados como coerentes e homogêneos, e que, portanto, o SCOT não oferece uma análise profunda sobre as assimetrias de poder que se conformam entre e dentro de tais grupos sociais (Russell, 1986; Rosen, 1993; Klein e Kleinman, 2002). Ademais, aponta-se que o fechamento das controvérsias sempre se dá a partir do alcance do consenso entre GSR sem que se explicitem as ferramentas para a análise de como a controvérsia entre diferentes grupos é efetivamente resolvida (Hard, 1993).

A outra abordagem proveniente da sociologia - ANT - oferece uma análise sistêmica de redes de produção tecnológica baseada na existência de atores, humanos e não humanos, elementos intermediários e elementos he- 
terogêneos, que se aliam ao redor de um projeto específico, elegendo, para tanto, um representante (ou porta-voz). Esse, através da tradução dos diferentes interesses relacionados ao projeto, envolve e mobiliza os demais atores da rede convencendo-os da importância e viabilidade de determinado artefato tecnológico em detrimento de artefatos concorrentes.

Assim, diferentemente da SCOT, a abordagem da ANT considera que o design final do artefato emerge não apenas porque ocorre o consenso entre GSR, mas, da mesma forma e com a mesma intensidade, devido à participação de atores heterogêneos e inanimados. Além disso, o conceito de tradução sanaria a falha da SCOT em se tratar imparcialmente os diferentes protagonistas inseridos em contextos de produção tecnológica, mesmo que um entre eles consiga impor sua vontade perante os demais.

Com base nisso, os autores da ANT reconhecem quatro principais etapas do processo de tradução: $a$. a problematização, em que ocorrem a definição do problema e o estabelecimento dos pontos de passagem obrigatórios para a solução do mesmo; $b$. o processo de atração, através do qual os atores buscam aprisionar outros atores em respectivos papéis propostos, criando mecanismos que possam ser colocados entre eles e outros atores que queiram definir suas identidades de uma outra forma; $c$. o processo de envolvimento, que define e atribui uma gama de papéis interrelacionados aos atores que os aceitaram; e $d$. o processo de mobilização, a partir do qual o porta-voz, que irá representar os interesses da coletividade, é eleito. Similarmente ao conceito de obstinação, da SCOT, e aos conceitos de pathdependence, irreversibilidade e lock-in, da $\mathrm{EE}$, o processo de tradução fixa alianças em determinada rede, tornando-a estável e originando o processo de irreversibilidade das escolhas tomadas em momento anterior.

É possível concluir, com base nessa breve exposição, que as três abordagens possuem interfaces que não podem ser desconsideradas e, portanto, pontos de análise similares e também complementares, que, se utilizados em conjunto, favoreceriam uma apreciação mais abrangente e ampla em estudos de caso de produção de artefatos tecnológicos. Ou seja, as categorias de uma abordagem podem, em parte, suprimir a debilidade analítica de outra. A Tabela 1 esquematiza os principais "pontos fracos" da capacidade explicativa de cada uma das abordagens tratadas nesse artigo, configurados na forma de críticas. ${ }^{2}$

2. Nessa tabela estão esquematizadas as fragilidades e os pontos complementares apontados tanto pelos autores de artigos que tratam as abordagens EE, SCOT e ANT, quanto por reflexões próprias. 
Tabela 1

Principais críticas aos conceitos da EE, SCOT e ANT

\begin{tabular}{|c|c|c|}
\hline & Conceitos & Principais críticas \\
\hline \multirow{6}{*}{ 出 } & (1) Ambiente de selecãof & (1a) Engloba caracteristicas de cunho estritamente econômico. \\
\hline & Seleção natural & (1b) Elmina qualquer caráter do trabalho humano. \\
\hline & $\begin{array}{l}\text { (2) Trajetórias naturaisf } \\
\text { Trajetórias tecnológicas }\end{array}$ & $\begin{array}{l}\text { Não explica por que os agentes investem em determinados caminhos e padrões de } \\
\text { mudança tecnológica. Jeterminadas exclusivamente por forças técnicas. }\end{array}$ \\
\hline & $\begin{array}{l}\text { (3) Regimes tecnológicos/ } \\
\text { Paradigmas tecnológicos }\end{array}$ & $\begin{array}{l}\text { Não explica por que dada tecnologia se torna paradigmática e não outras co- } \\
\text { existentes. }\end{array}$ \\
\hline & $\begin{array}{l}\text { (4) Path-dependence, } \\
\text { Irreversibilidade e Lock-in }\end{array}$ & $\begin{array}{l}\text { Uma vez traçada a trajetória tecrológica, a interdependência entre os } \\
\text { componentes que a constituem impossibilita o retorno ao caminho anterior ou a } \\
\text { uma nova trajetória. }\end{array}$ \\
\hline & (5) SNis $\in$ SSIs & $\begin{array}{l}\text { Visão institucionalizada e pré-definida do papel dos agentes na produçāo } \\
\text { tecnológica. }\end{array}$ \\
\hline \multirow{6}{*}{8} & & $\begin{array}{l}\text { (1a) Não oferece análise sócio-econômica sobre os GSR, nem sobre as astimetrias } \\
\text { de poder. }\end{array}$ \\
\hline & (GSR)/ Contexto mais amplo & (1b) Pressupõe interesses coerentes e homogêneos. \\
\hline & & $\begin{array}{l}\text { (1c) Produção tecnológica vista simplesmente como resultado do consenso entre } \\
\text { GSR. }\end{array}$ \\
\hline & $\begin{array}{l}\text { (2) Flexibilidade } \\
\text { Interpretativa/ Controvérsias } \\
\text { Tecnológicas }\end{array}$ & $\begin{array}{l}\text { Falha no provimento de ferramentas para a análise de como a controvérsia entre } \\
\text { diferentes grupos é resolvida. }\end{array}$ \\
\hline & (3) Fechamento/Estabilização & Abrem espaço para o relativismo. \\
\hline & $\begin{array}{l}\text { (4) Estrutura tecrológica/ } \\
\text { Obstinação }\end{array}$ & Não é aplicada como conceito analítico a todos os casos da abordagem. \\
\hline \multirow{5}{*}{$\sum_{<}^{\frac{1}{\alpha}}$} & (1) Redes & $\begin{array}{l}\text { Não permite um adequado tratamento das estruturas e mecanismos de poder que } \\
\text { se estabelecem dentro de uma rede. }\end{array}$ \\
\hline & (2) Atores & $\begin{array}{l}\text { (2a) Não estẫo caracterizados em seus contextos social, organizacional ou } \\
\text { institucional. }\end{array}$ \\
\hline & & (2b) Abordagem não considera ações causais por parte dos atores de uma rede. \\
\hline & (3) Traduçã̃o & $\begin{array}{l}\text { Não explica por que atores favorá veis ao desenvolvimento do artefato fracassaram } \\
\text { ao tentar envolver outros atores. / Não abrange a apreciaçăo da "continuidade" no } \\
\text { desenvolvimento tecnológico. }\end{array}$ \\
\hline & $\begin{array}{l}\text { (4) Irreversibilidade da } \\
\text { tradução }\end{array}$ & Alega impossibilidade de mudanças na rede estável. \\
\hline
\end{tabular}

Fonte: Elaboração própria a partir de Bruun \& Hukkinen (2003), MacKenzie (1992), Vergragt (1988), Rosen (1993), Russell (1986), Klein e Kleinman (2002), Hard (1993) entre outros.

Por pontos de análise similares entendem-se aqueles que, apesar de pertencerem a abordagens distintas, caminham numa mesma direção para a compreensão do processo de produção tecnológica, ou seja, açambarcam as mesmas razões e condicionantes, tais como aqueles que se apresentam na Tabela 2. 
Tabela 2

Pontos de análise similares

\begin{tabular}{|c|c|c|c|}
\hline EE & SCOT & ANT & Características \\
\hline I) SNis/SSIs & GSRs & Redes & $\begin{array}{c}\text { Interaçöes que se estabelecem para a } \\
\text { criacão de novas tecnologias. }\end{array}$ \\
\hline $\begin{array}{c}\text { II) Path-dependence, } \\
\text { Irreversibilidade e Lock-in }\end{array}$ & Obstinação & $\begin{array}{c}\text { Irreversibilidade da } \\
\text { tradução }\end{array}$ & $\begin{array}{c}\text { Processos que fixam as alianças } \\
\text { estabelecidas em daco sistema, gfupo ou } \\
\text { rede. }\end{array}$ \\
\hline ili) Regimes tecnológicos & $\begin{array}{c}\text { Estruturas } \\
\text { tecnológicas }\end{array}$ & - & $\begin{array}{c}\text { Conhecimentos, objetivos e técnicas } \\
\text { empregados na prociução tecnológica. }\end{array}$ \\
\hline
\end{tabular}

Fonte: Elaboração própria.

No primeiro grupo de conceitos similares, apresentam-se aqueles que, sob diferentes perspectivas, denotam os ambientes ou as interações que se estabelecem para a criação de novas tecnologias, sejam estes sob a forma de sistemas, grupos ou redes. No segundo grupo, encontram-se os conceitos que designam os processos que fixam as alianças estabelecidas nesses sistemas, grupos ou redes. Já no terceiro grupo de conceitos similares, destacam-se um conceito proveniente da EE e outro proveniente da SCOT, que representam o conjunto de conhecimentos, objetivos e técnicas empregados no processo de produção tecnológica.

Por fim, a Tabela 3 apresenta os conceitos complementares que, justamente pelo fato de não caminharem numa direção comum na análise dos condicionantes da produção tecnólogica poderiam suprir algumas fragilidades analíticas apontadas aos conceitos das outras abordagens.

O primeiro grupo de conceitos complementares define as interações estabelecidas no processo de produção tecnológica e inclui os conceitos de ambiente de seleção e seleção natural da EE. Estes definem uma visão institucionalizada e predefinida do papel dos agentes, com base numa dinâmica "natural", independente de qualquer componente social, e aproximam-se dos conceitos de GSR e, em contexto mais amplo, da SCOT, que se referem aos meios sociocultural e político do processo de produção tecnológica. Os conceitos de redes e de tradução, da ANT, por sua vez, destacam o papel de atores não humanos e o papel do "porta-voz" responsável por traduzir os desejos da coletividade.

No segundo grupo de conceitos complementares, que refletem os processos pelos quais é definida a tecnologia, encontram-se os conceitos de trajetórias naturais e trajetórias tecnológicas, determinadas por uma lógica técnica inerente, conforme os definem a EE. Por sua vez, os conceitos de flexibilidade interpretativa e controvérsias tecnológicas da abordagem SCOT podem ser considerados complementares aos da EE, na medida em que 
agregam a possibilidade de múltiplas interpretações sobre o artefato e o alcance do consenso entre seus diferentes significados. O conceito de tradução da ANT, que agrega a possibilidade da mobilização dos atores envolvidos na persistência do padrão da mudança tecnológica, adiciona ainda maior poder explicativo à análise.

Finalmente, no terceiro grupo que se refere aos mecanismos a partir dos quais o processo de produção tecnológica se define, encontram-se os conceitos de regimes e paradigmas tecnológicos, da EE. Estes têm sido criticados por desconsiderarem os processos sociais que poderiam levar ao paradigma e poderiam, portanto, ser complementados pelos conceitos propostos pela SCOT de fechamento e estabilização, que avaliam se o artefato é eleito justamente com base na resolução das controvérsias entre os GSR. Agrega também poder explicativo a ideia de momentos da tradução da ANT, que reflete os processos sinalizadores das trajetórias a partir das quais o progresso tecnológico se torna possível, viabilizado pela presença de um porta-voz.

Tabela 3

Pontos de análise complementares

\begin{tabular}{|c|c|c|c|}
\hline & $\mathrm{EE}$ & SCOT & ANT \\
\hline \multirow{2}{*}{$\begin{array}{c}\text { Grupol } \\
\text { Características }\end{array}$} & $\begin{array}{l}\text { Ambiente de seleção/ } \\
\text { Selecão natural }\end{array}$ & GSRs/ Contexto mais amplo & Redes/Tradução \\
\hline & $\begin{array}{l}\text { Dinâmica natural, que } \\
\text { independe de qualquer } \\
\text { componente social. }\end{array}$ & $\begin{array}{l}\text { Abrange os meios sócio-cultural e } \\
\text { político, mas não considera as } \\
\text { diferentes estruturas de poder. }\end{array}$ & $\begin{array}{c}\text { Redes de atores humanose } \\
\text { não-humanos traduzem seus } \\
\text { interesses. }\end{array}$ \\
\hline \multirow{2}{*}{$\begin{array}{l}\text { Grupo } \| \\
\text { Características }\end{array}$} & $\begin{array}{l}\text { 11) Trajetórias naturais/ } \\
\text { Trajetorias tecnologicas }\end{array}$ & $\begin{array}{l}\text { Flexibilidade interpretativa/ } \\
\text { Controversias tecnologicas }\end{array}$ & Tradução \\
\hline & $\begin{array}{l}\text { Orientadas exclusivamente } \\
\text { por forças técnicas. }\end{array}$ & $\begin{array}{l}\text { Possibilidade de múltiplas } \\
\text { interpretaçōes sobre o artefato. }\end{array}$ & $\begin{array}{l}\text { Mobilização dos atores } \\
\text { envolvidos na persistência do } \\
\text { padrão da mudança } \\
\text { tecnológica. }\end{array}$ \\
\hline \multirow{2}{*}{$\begin{array}{l}\text { Grupo III } \\
\text { Características }\end{array}$} & $\begin{array}{l}\text { III) Regimes tecnológicos/ } \\
\text { Paradigmas tecnológicos }\end{array}$ & Fechamento/Estabilização & Momentos da Tradução \\
\hline & $\begin{array}{c}\text { Não faz referência aos } \\
\text { processos sociais que levam } \\
\text { ao paradigma. }\end{array}$ & $\begin{array}{l}\text { Artefa to é eleito com base na } \\
\text { resolução das controvérsias dos } \\
\text { GSRs. }\end{array}$ & $\begin{array}{c}\text { Processos sinalizadores das } \\
\text { trajetórias a partir das quais o } \\
\text { progresso tecnológico se torna } \\
\text { possivel. }\end{array}$ \\
\hline
\end{tabular}

Fonte: Elaboração própria.

Na próxima seção, são brevemente apresentados estudos de casos sob a perspectiva das três abordagens sugeridas nesse artigo. Nela, além de identificarmos a forma distinta como cada abordagem compreende o processo de produção tecnológica, são propostas algumas possibilidades de complementaridade entre as análises, utilizando-se os conceitos provenientes das demais abordagens consideradas. 


\section{Estudos de casos de tecnologias}

\section{provenientes da matriz energética elétrica ${ }^{3}$}

Nesta seção são explorados três casos de produção de tecnologias que utilizam a matriz energética elétrica, cada um deles sob o olhar de uma das três abordagens apresentadas na seção anterior. A partir de então, é possível comparar as diferentes formas com que cada qual analisa processos similares (no caso produção de artefatos tecnológicos que utilizam energia elétrica) e, assim, identificar como esses diferentes enfoques analíticos poderiam se complementar.

No primeiro deles, sob a perspectiva da abordagem SCOT, Ruth Cowan (1993) analisa o embate entre as duas principais técnicas de refrigeração existentes no início do século XX nos Estados Unidos: energia elétrica e gás.

Os principais GSR envolvidos na construção da tecnologia foram os fabricantes de refrigeradores elétricos: GE, Westinghouse, Kelvinator e Frigidaire, e a maior fabricante de refrigeradores a gás: Servel. Dentre esses grupos, as estratégias corporativas tomadas pela GE foram, de acordo com a autora, o fator que propiciou um alto grau de penetração da empresa no mercado doméstico norte-americano, originando os processos de fechamento e estabilização do refrigerador elétrico.

As estratégias da GE basearam-se em componentes de caráter estritamente econômico como: $a$. o fato de já dominar quase todas as tecnologias baseadas em eletricidade da indústria norte-americana; $b$. ter iniciado mais cedo a fabricação de refrigeradores elétricos em larga escala; e $c$. ter baseado suas estratégias de venda e de difusão de refrigeradores na publicidade do produto e na garantia de uma rede de assistência técnica e de distribuidores franqueados.

Além desses fatores, a autora explora a influência do contexto mais amplo na conformação da tecnologia, ao mencionar as controvérsias tecnológicas e os diferentes graus de inclusão na estrutura tecnológica do refrigerador a gás de engenheiros e consumidores. Os primeiros julgavam que o refrigerador a gás era tecnicamente muito mais adequado ao uso doméstico e os segundos, apesar de considerarem-no mais barato e de mais fácil manuseio, eram contrários ao uso de amônia como substância refrigeradora, o que requereria das fabricantes de refrigeradores a gás maiores investimentos em P\&D e propaganda para se adaptarem a essa demanda.
3. Esta classificação segue a denominação dada pelos próprios autores dos respectivos estudos e está de acordo com a metodologia proposta por Yin (1984) 
Essa controvérsia tecnológica relacionada ao artefato acabou eliminando, através do que os economistas evolucionários poderiam chamar de seleção natural, diversos fabricantes de refrigeradores a gás, deixando sozinha a Servel, que nunca conseguiu fazer frente aos fabricantes de refrigeradores elétricos, dominando apenas entre 8 e $10 \%$ do mercado total.

A autora argumenta que, apesar de engenheiros e consumidores delegarem um maior número de vantagens ao refrigerador a gás do que ao refrigerador elétrico, a penetração das estratégias de negócios dos fabricantes de refrigeradores elétricos foi determinante para o sucesso do artefato. No entanto, Cowan (1993) explora apenas superficialmente quais foram os processos determinantes para essa penetração, ou seja, a capacidade desses atores para traduzir seus interesses mobilizando os demais para consolidar acordos e alianças com diversos agentes.

Para complementar a análise da autora, é possível sugerir, por parte da ANT, o conceito de tradução associado ao conceito de estruturas de poder, já que a GE, mesmo que embasada em estratégias corporativas e se aproveitando do período de expansão elétrica no país, se fortaleceu à medida que conseguiu aliar ao redor de seus interesses de promoção do refrigerador elétrico os demais atores da rede, como fabricantes, fornecedores de energia elétrica, além das redes de assistência técnica e de distribuidores franqueados.

Além disso, ao inserir o papel das estratégias corporativas da GE, principalmente voltadas à formação dessas alianças, esse estudo de caso já se aproxima bastante dos conceitos oferecidos pela abordagem EE. Dessa forma, é possível agregar as relações usuário-produtor e os acordos cooperativos citados pela EE à análise da autora, provendo ferramentas que identifiquem como as controvérsias entre os diferentes grupos se estabeleceram e de que forma elas foram solucionadas.

No caso do veículo elétrico (VEL) explorado pela abordagem ANT, Michel Callon (1980) analisa a rede de atores que se estabelece ao redor do projeto de desenvolvimento desta tecnologia, bem como os interesses de cada ator no projeto. Essa rede era formada por:

a. Électricité de France (EDF), empresa estatal de energia elétrica, que se posicionava no centro do sistema, procurando apoio e legitimação dos demais atores no desenvolvimento do VEL; 
b. Estado francês, sob a figura da Délégation Générale à la Recherche Scientifique et Technique (DGRST) e do Ministério da Qualidade de Vida (MQV), que tinha um posicionamento passivo e dividido, e hesitantemente apoiava os interesses de desenvolvimento do VEL;

c. Institut Français du Pétrole (IFP), interessado no desenvolvimento de células combustíveis de alta temperatura, aplicáveis à indústria petrolífera;

d. acadêmicos que se dividiam com relação ao projeto e procuravam evitar perdas e garantir a sobrevivência de suas equipes de pesquisa;

e. industriais, que estavam pouco interessados na exploração de um mercado limitado e hipotético como o do VEL, naquele momento;

f. governos municipais, que apoiavam o desenvolvimento dos ônibus elétricos, que solucionariam seus problemas urbanos;

g. pequenas empresas que, devido ao fato de serem totalmente dependentes dos governos municipais, vislumbraram uma oportunidade interessante para si; e

h. consumidores que, devido ao fato de serem indiferentes ao tipo de combustível que abasteceria seus veículos, pouco participaram do debate em torno do VEL.

O autor sugere duas principais razões para o fracasso do VEL:

a. o resultado de iniciativas provenientes da EDF, que procuraram a todo o momento apoio e legitimidade, mas não conseguiram articular os atores na indústria, na academia, no mercado consumidor e no próprio governo; e

b. a ausência de análise estratégica de um governo incapaz de identificar possíveis desenvolvimentos técnico-científicos advindos do projeto e que, ao mesmo tempo, deixou-se manipular pelos vários atores protagonistas envolvidos.

Na visão de Callon (1980), essas características reduziram consideravelmente a margem de manobra e a capacidade de iniciativa do governo francês, que estava completamente permeado por análises e projetos realizados fora 
de seu próprio contexto, sendo incapaz de introduzir no debate novos pontos de vista e protagonistas esquecidos do sistema, como os pequenos inovadores e consumidores.

Além disso, o papel que o Estado deveria assumir, ajustando necessidades e recursos e reconciliando interesses contraditórios, foi substituído, nesse sistema, por um papel essencialmente legitimador, transformando em desejo coletivo projetos particulares que ele concordou em assumir.

Explicita-se nesta análise, portanto, a importância do elemento "tradução" na determinação do fracasso do artefato. Mais do que isso, é possível considerar que a abordagem ANT coloque acima de qualquer outra argumentação o fato de que o VEL pereceu naquele momento do cenário francês pela incapacidade de um ator específico dessa rede em "vender" o projeto desse artefato aos demais. Dessa forma, o autor se afastaria, por exemplo, de uma perspectiva economicista possível na qual o fracasso fosse fruto da trajetória natural da indústria automobilística, em que o veículo à gasolina assume a posição de paradigma tecnológico em detrimento do VEL.

Em contrapartida, percebemos aqui elementos que se aproximam da abordagem SCOT, como o fato de que o fechamento (no caso, o fracasso do VEL) ocorre em meio aos conflitos de interesses entre os GSR (ou atores) que possuem interpretações próprias sobre o artefato, assim como ao fato de que os diversos atores da rede não estavam incluídos, naquele momento, na estrutura tecnológica do projeto da EDF. Assim, ao encontrar-se isolada na defesa da pesquisa de células combustíveis de baixa temperatura, a EDF não conseguiu solidificar interações entre atores em torno dessa estrutura tecnológica específica, que se configuraria no VEL.

No entanto, Callon (1980) vai além da abordagem SCOT ao agregar aos conflitos de interesses e às diferentes interpretações sobre o artefato as diferentes estruturas de poder que se estabelecem na rede, mesmo que o ator mais poderoso - o Estado - estivesse enfraquecido pela insistência em assumir o papel de conciliador entre as partes.

Com isso, é possível considerar o estudo de caso da ANT como pertencente a um nível intermediário de análise, que não se abastece inteiramente nem de fatores relacionados ao ambiente estritamente social, que interfere na construção do artefato tecnológico com suas diversas interpretações e visões do 
mesmo - como o que se daria a partir de uma abordagem SCOT -, nem de fatores relacionados ao ambiente estritamente econômico, em que o papel do Estado estaria reduzido em favor de uma lógica natural e inerente de produção tecnológica - como ocorreria numa análise EE.

Além de ter sido explorado pela abordagem ANT, o VEL também foi objeto de estudo da EE. Contudo, enquanto Callon (1980) enfoca o posicionamento dos atores da rede francesa em seu processo de criação, desenvolvimento e fracasso, os economistas Robin Cowan e Staffan Hultèn (1996) analisam os fatores que possibilitariam, a partir do estabelecimento de um processo regulatório que estimulasse a produção em massa desse artefato, o escape do aprisionamento (lock-in) à tecnologia dos veículos à gasolina no mercado automobilístico que perdura há mais de um século.

Ao tomar por referência a abordagem ANT, os autores mencionam a formação de duas principais redes que se estabeleceram em torno da indústria automobilística e que foram de extrema importância para os rumos tomados, tanto na origem como na consolidação da indústria de veículos à gasolina.

$\mathrm{Na}$ origem da indústria automobilística, destacam a presença de elementos, como $a$. a Electric Vehicle Company e os produtores de veículos elétri$\cos ; b$. Thomas Edison, representando o papel de técnicos e engenheiros relacionados ao artefato; c. a patente "Selden", que se configurou num trunfo para a conformação da indústria Ford de veículos à gasolina; e $d$. a variável preço, que foi fundamental para a disseminação do veículo à gasolina nos primeiros momentos daquela indústria.

Já no segundo momento, os autores apontam: $a$. a criação de redes de postos de abastecimento à gasolina; $b$. o crescimento da indústria de refino de petróleo; e c. o surgimento de uma rede de assistência automecânica especializada nesse tipo de veículo, que deram sustentação e permitiram a consolidação dessa indústria.

Apesar de considerarem elementos heterogêneos na composição dessas redes, portanto de se aproximarem do conceito de redes de atores da ANT, Cowan e Hultèn (1996) ignoram elementos importantes para essa abordagem, como a forma a partir da qual esses atores conseguiram traduzir seus interesses e mobilizar os demais atores em direção a eles, ou, em contrapartida, considerar como esses atores poderiam mobilizar a rede para escapar do lock-in e se voltar para tecnologias automotivas alternativas. 
Assim, com base na abordagem SCOT, é possível inserir os conceitos de GSR e de contexto mais amplo, mais especificamente dos interesses de outros grupos sociais que não exclusivamente os grupos organizacionais, como o posicionamento de ONGs ambientais, por exemplo. A inclusão desses conceitos agregaria uma compreensão maior dos diferentes tipos de interpretações e de conflitos de interesses relacionados ao artefato, que influenciariam o alcance do fechamento e da estabilização de tecnologias automobilísticas alternativas.

Ao contrário, a trajetória tecnológica da indústria automobilística no período estudado (1885-1998) foi analisada como determinada exclusivamente por fatores técnico-econômicos, como as estratégias de negócios (conformação de alianças com a indústria de refino de petróleo e distribuição, bem como com uma rede de assistência automecânica especializada nesse tipo de veículo), as vantagens técnicas e os preços mais baixos dos veículos à gasolina quando comparados ao VEL.

Vê-se assim que é possível complementar a análise dessa trajetória, com conceitos da abordagem SCOT, como:

a. poder (com base em Bijker, 1995): os fatores técnico-econômicos acima citados acabaram fixando os significados associados ao veículo à gasolina e os pontos de passagem obrigatórios criados com alianças com a indústria de refino de petróleo e distribuição e com uma rede de assistência automecânica especializada nesse tipo de veículo. Esse é um exemplo de assimetria de poder entre agentes, porque eles disciplinaram efetivamente a interação dos atores, reforçando essa trajetória e iniciando o processo de estabilização tecnológica e, portanto, da conformação do paradigma tecnológico;

b. flexibilidade interpretativa: os questionamentos relacionados ao veículo à gasolina que surgiram no início dos anos 1970 poderiam ser considerados como um processo de redefinição do problema relacionado aos constrangimentos técnicos do VEL, podendo, assim, afastar a indústria automobilística da rigidez da trajetória relacionada ao veículo à gasolina.

Além desses conceitos da abordagem SCOT, podemos agregar, ainda, os conceitos da ANT de:

a. formação de redes estáveis; e 
b. tradução, pois, devido ao fato de não se aterem aos conflitos de interesses entre os atores-chave no momento da criação dos veículos automotores, os autores acabam não questionando o modo como cada grupo de fabricantes traduzia seus projetos e como ganhava credibilidade. Para eles, o fator fundamental no processo concorrencial entre as tecnologias foi, num primeiro momento, a variável preço e, em seguida, as assimetrias técnicas que se formavam entre os três tipos de veículos.

Esses fatores técnico-econômicos, de acordo com Cowan e Hultèn (1996), fortaleceram e consolidaram a indústria de veículos à gasolina de tal forma que mesmo os questionamentos sociais e ambientais relacionados a essa tecnologia que sugiram nos anos 1970 não conseguiram abalar a sua trajetória, levando, assim, ao estabelecimento do paradigma e ao alcance do lock-in dessa tecnologia. Esses elementos estruturaram e estabilizaram as estruturas tecnológicas relacionadas aos artefatos e tornaram seus embricamentos mais obstinados, ou, como poderia sugerir a ANT, levaram a um processo de irreversibilidade da tradução dos interesses relacionados a elas.

Para escapar desse aprisionamento, os autores sugerem a introdução de componentes regulatórios ou o alcance da superação da capacidade de estocagem energética das baterias elétricas disponíveis no mercado.

Também com relação a esses conceitos, podemos incluir, com base na abordagem SCOT, os conceitos de:

a. flexibilidade interpretativa, pois abre a oportunidade para que o lock-in seja revertido com base na redefinição do problema original relacionado ao VEL, ou seja, dos constrangimentos técnicos de suas baterias, que se relacionam à incapacidade de percorrer longas distâncias; e, complementarmente,

b. inclusão de diferentes estruturas tecnológicas aplicadas à resolução do problema, não necessariamente relacionadas à estrutura tecnológica trilhada em momento anterior.

Por outro lado, a abordagem da ANT complementa os conceitos da EE ao considerar:

a. o caráter de negociabilidade da tecnologia, que ocorre com a tradução dos interesses dos diversos atores, que, voltados a tecnologias auto- 
motivas alternativas, poderiam incentivar a produção em massa de VELs e, com isso, ocasionar o escape do lock-in; e

b. a possibilidade de reversão das escolhas tomadas em momento anterior.

\section{Conclusões}

Apesar de serem casos bastante similares, o primeiro tratando do surgimento do refrigerador elétrico nos Estados Unidos e os outros dois da criação do veículo elétrico, um na França e outro também nos Estados Unidos, os enfoques analíticos utilizados são bastante diferentes.

Nos casos tratados pelas abordagens provenientes da sociologia, a análise se refere ao período de construção das tecnologias em que foram se apresentando os embates de forças entre os GSR (ou atores) e seus respectivos interesses, até o momento em que se alcança o fechamento da controvérsia (no caso do refrigerador elétrico), ou o momento em que as alianças entre os atores da rede se enfraquecem e o fechamento do artefato não é alcançado (no caso do VEL).

Por outro lado, no caso do veículo elétrico tratado pela $E E$, os autores dessa corrente preferiram fazer uma revisão da trajetória da indústria automobilística desde final do século XIX para compreender as razões do lock-in que se estabeleceu no paradigma do veículo à gasolina, para então prescreverem soluções para se escapar desse aprisionamento, que se baseavam, principalmente em regulamentações favoráveis à produção em massa de automóveis não poluentes como o VEL.

Similarmente, as três abordagens tratam de embates entre tecnologias concorrentes (apesar de EE não enfatizar estritamente esse aspecto da análise): refrigerador a gás $x$ refrigerador elétrico e veículo à gasolina $x$ VEL, em que uma tecnologia é eleita (ou torna-se paradigmática) a despeito de outras. No entanto, as diferentes explicações encontradas para o sucesso ou o fracasso dessas tecnologias são justamente o componente que faz com que cada uma das abordagens possa, de alguma forma, complementar a análise da outra.

Assim, no caso do refrigerador elétrico da abordagem SCOT, as estratégias organizacionais de penetração no mercado de refrigeração encabeçadas pela $\mathrm{GE}$, somadas às controvérsias tecnológicas relacionadas ao fato de que 
o refrigerador a gás utiliza amônia, foram os fatores responsáveis pelo sucesso da refrigeração elétrica. No caso do VEL, por parte da ANT, o fracasso ocorre pela incapacidade da EDF em traduzir seus interesses aos demais atores da rede francesa e, por parte da $E E$, devido às estratégias organizacionais dos fabricantes de veículos à gasolina, às vantagens técnicas e aos preços mais baixos deste quando comparado ao VEL.

Porém, é razoável argumentar que, nos três casos, a consolidação do artefato tenha ocorrido devido a uma soma dessas três distintas razões, já que o refrigerador elétrico foi o design eleito, por exemplo, não só devido às controvérsias tecnológicas relacionadas ao artefato concorrente e às estratégias organizacionais da GE (já se aproximando bastante das razões encontradas pela EE para o sucesso do veículo a gasolina), baseadas na conformação de alianças com centrais elétricas e com uma rede de assistência técnica especializada nesse tipo de artefato, mas também porque a GE conseguiu traduzir aos demais atores da rede seus interesses (diferentemente do que ocorre com a EDF no caso VEL, de acordo com a análise da ANT), mobilizando-os em direção a eles.

Ao mesmo tempo em que dado enfoque analítico pode ser reconhecido de formas diferentes pelas três abordagens, também pontos de análise fracos podem ser fortalecidos a partir da incorporação de ferramentas das demais abordagens. Assim, onde a EE não reconhece a possibilidade de outras formas de escape do lock-in, que não através de processos regulatórios, por exemplo, as abordagens SCOT e ANT agregam o caráter de flexibilidade interpretativa e de negociabilidade da tecnologia, bem como a possibilidade de inclusão em diferentes estruturas tecnológicas e de reversão das escoIhas tomadas em momento anterior, para indicar a possibilidade do estabelecimento de interesses em torno de tecnologias automotivas alternativas e, com isso, do escape do aprisionamento em torno do veículo à gasolina.

Por sua vez, onde a ANT apenas reconhece o papel do componente tradução na determinação do fracasso do VEL, a EE vislumbraria que o fracasso do VEL fosse fruto da trajetória natural da indústria automobilística na qual o veículo à gasolina assume, devido a fatores organizacionais, técnicos e econômicos, a posição de paradigma tecnológico em detrimento do VEL. E a abordagem SCOT, por sua vez, reconheceria na ausência de consenso nas controvérsias tecnológicas, bem como nos diferentes graus de inclusão na estrutura tecnológica do VEL, o fracasso da rede estabelecida em torno do projeto da EDF. 
Dessa forma, o principal argumento defendido neste artigo é o de que o tradeoff de escolha analítica de produção tecnológica entre abordagens estritamente econômicas versus aquelas estritamente sociológicas, tradicionalmente vistas como inconciliáveis, não é inexorável. É possível - além de desejável - adotar referenciais e metodologias interdisciplinares de análise, que permitem reconhecer as diferentes faces - e fases - de um mesmo processo, garantindo uma caracterização mais ampla e abrangente do objeto analisado.

Abstract: It is generally accepted that analyses of knowledge production and technological artifacts lack a multidisciplinary approach. Particularly the interaction is very weak between analysts who adopt sociological approaches and those who study scientific knowledge and technological artifacts from an economic perspective. This article reports an attempt to integrate these two modes of analysis, identifying the main differences and convergent points between them. It is argued that while Economics overlooks important elements for the understanding of these processessuch as the interests of the social actors, the power structures and the influence of the political aspects - Sociology, disregards many of the basic economic aspects of technological production, such as economic agencies, institutions and systems. The result is the occurrence of vague spaces of analysis that could be better explored if a complementary effort existed between both disciplines. This study explores the possibilities of dialogue between one approach of Economics thought, represented by the Evolutionary Economics (EE), and two approaches of the Sociology of Scientific Knowledge, represented by the Social Construction of Technology (SCOT) and the Actor Network Theory (ANT), arguing that the analytical categories of each approach may complement the others, thus allowing a more consistent characterization of the production of technological artifacts. Keywords: Technological production, Evolutionary Economics, Sociology of Technology.

\section{Referências}

BIJKER, W. (1987) "The social construction of bakelite: Toward a theory of invention", in: Bijker, W.; Hughes, T.; Pinch, T., The social construction of technological systems - New directions in the sociology and history of technology. Cambridge: MIT.

- - . (1995) of bicycles, bakelites and bulbs: Toward a theory of sociotechnical change, Cambridge (MA)/Londres: MIT Press. 
BruUn, H. \& HuKkinen, J. (2003) “Crossing boundaries: An integrative framework for studying technological change". Social Studies of Science, Vol. 1, n. 33.

Callon, M. (1980) "The State and technical innovation: A case study of the electrical vehicle in France". Research Policy, n. 9.

Coombs, R.; Saviotti, P. \& Walsh, V. (1992) "Technology and the firm: The convergence of economic and sociological approaches?", in Coombs, R.; Saviotti, P. \& Walsh, V., Technical change and company strategies: Economic and sociological perspectives. Londres: Harcourt Jovanovich.

Cowan, R. (1993) "How the refrigerator got its hum", in Mackenzie, D.; Wajcman, J. (eds), The social shaping of technology: How the refrigerator got its hum. Open University Press, Milton Keynes.

Cowan, R. \& Hultèn, S. (1996) "Escaping lock-in: The case of electric vehicle". Technological Forecasting and Social Change, Vol. 53.

Dosı, G. (1982) "Technological paradigms and technological trajectories: A suggested interpretation of the determinants of technological change". Research Policy, Vol. 11.

Freeman, C. (1984) "Prometheus unbound”. Futures, Vol. 16, n. 5.

HARD, M. (1993) "Beyond harmony and consensus: A social conflict approach to technology", Science, Technology and Human Values. Vol. 18, n. 4.

Klein, H. \& Kleinman, D. (2002) "The social construction of technology: Structural considerations". Science, Technology, \& Human Values, Vol. 27, n. 1.

LundvalL, B. (1988) "Innovation as an interactive process: From user-producer interaction to the national system of innovation", in Dosi, G.; Freeman, C.; Nelson, R.; Silverberg, G. \& Soete, L. (eds). Technical change and economic theory, Londres: Pinter.

- - - (1992) National systems of innovation: Towards a theory of innovation and interactive learning. Londres: Printer Publisher.

Mackenzie, D. (1992) "Economic and sociological explanation of technical change", in Coombs, R.; Saviotti, P. \& Walsh, V., Technical change and 
company strategies: Economic and sociological perspectives. Londres: Harcourt Jovanovich.

MalerbA, F. (2002) "Sectoral systems of innovation and production". Research Policy, Vol. 31.

Nelson, R. \& Winter, S. (1977) "In search of useful theory of innovation". Research Policy, Vol. 6.

- - (1982) An evolutionary theory of economic change. Cambridge (MA): Harvard University Press.

Rosen, P. (1993) "The social construction of mountain bikes: Technology and postmodernity in the cycle industry". Social Studies of Science, Vol. 23, n. 3.

Rosenberg, N. (1982) Inside the black box: Technology and economics. Cambridge: Cambridge University Press.

RusseL, S. (1986) "The social construction of artefacts: A response to pinch and bijker". Social Studies of Science, Vol. 16.

UtTerback, J. (1996) Dominando a dinâmica da inovação. Rio de Janeiro: Qualitymark.

Vergragt, P. (1988) "The social shaping of industrial innovations". Social Studies of Science, Vol. 18.

YIN, R. K. (1984) Case study research - Design and Methods. Beverly Hills, California: Sage Publications. 